\title{
Freenet: direitos e liberdade na internet
}

\section{Freenet: rights and freedom on the internet \\ Freenet: derechos y libertad en internet}

Diogo Moyses | diogomoyses@gmail.com

Consultor independente. São Paulo, SP, Brasil.

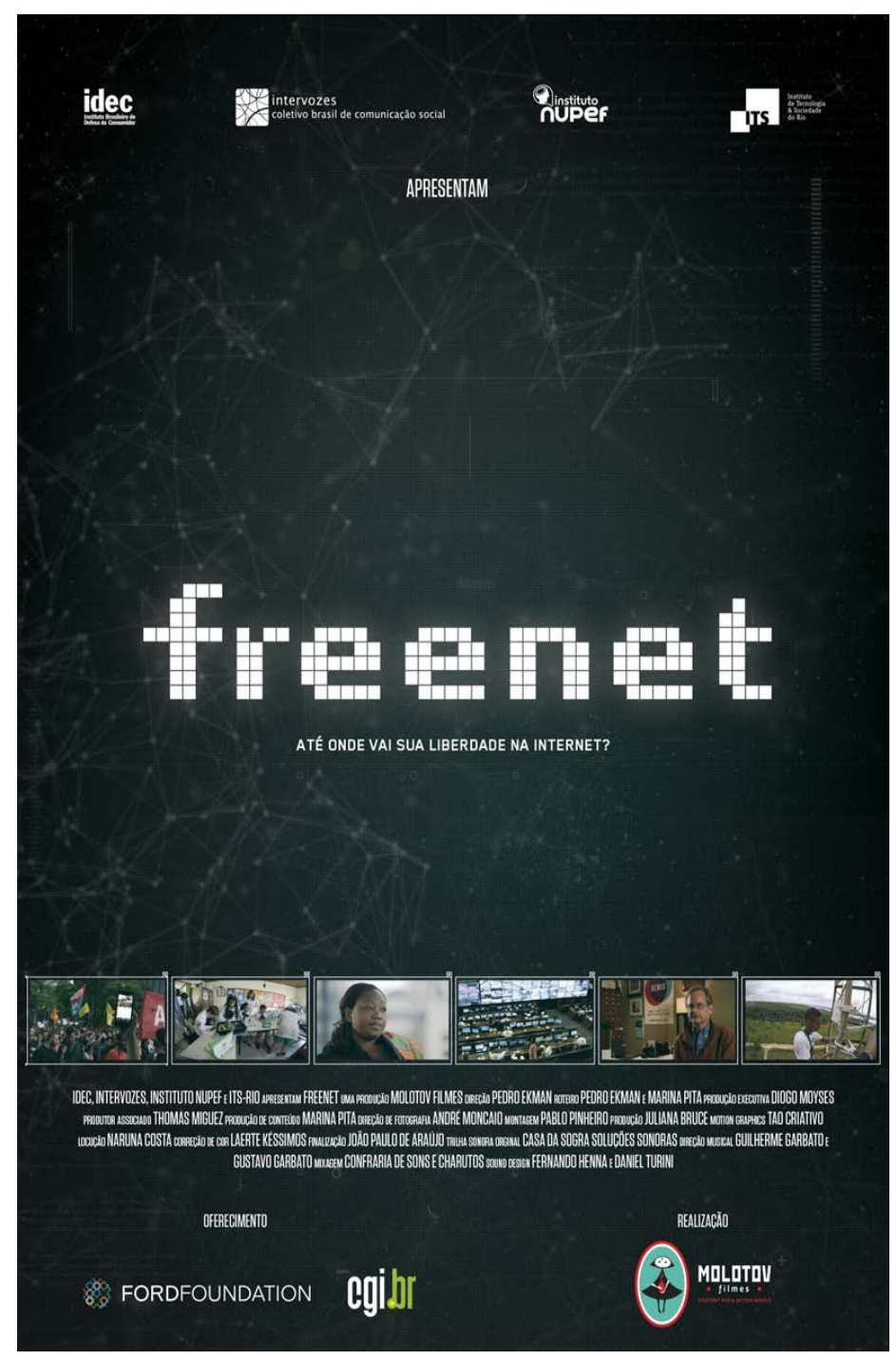

Palavras-chave: internet; comunicação; democracia; liberdade de expressão; privacidade; neutralidade de rede.

Keywords: internet; communication; democracy; freedom of expression; privacy; net neutrality.

Palabras clave: internet; comunicación; democracia; libertad de expresión; privacidad; neutralidad de red.

i Para saber mais sobre o filme, acesse os seguintes sites: https://www.freenetfilm.org.br/ | https://vimeo.com/161511483

https://www.youtube.com/watch?v=TSomRix04fQ | https://www.facebook.com/FreenetFilm/ 
Contribuição dos autores: 0 autor é responsável pelo artigo

Declaração de conflito de interesses: o autor é produtor executivo do filme, sem interferência em seu conteúdo editorial. Fontes de financiamento: Não há.

Histórico do artigo: Submetido: 13.set.2016 | Aceito: 15.set.2016 | Publicado: 30.set.2016.

Licença CC BY-NC atribuição não comercial. Com essa licença é permitido acessar, baixar (download), copiar, imprimir, compartilhar, reutilizar e distribuir os artigos, desde que para uso não comercial e com a citação da fonte, conferindo os devidos créditos de autoria e menção à Reciis. Nesses casos, nenhuma permissão é necessária por parte dos autores ou dos editores.

Desde o final do século XIX, as comunicações vêm adquirindo importância central na vida dos indivíduos e das sociedades. Dos primeiros telégrafos à internet em alta velocidade, diversos serviços surgiram e se consolidaram - entre eles a telefonia fixa, o rádio e a televisão -, evidenciando a notável força dos meios de comunicação nos diferentes aspectos da vida social, econômica, cultural e política, com impactos até hoje investigados pelos diversos campos das ciências humanas. Mais recentemente, com o surgimento da TV por assinatura, da telefonia móvel e, o que é mais importante, da internet, multiplicaram-se os meios e as formas de participação dos cidadãos no fluxo de troca de informações. Graças aos computadores, aos celulares, aos novos recursos que permitem a comunicação em rede, pessoas têm condições de produzir e trocar informações em tempo real, independentemente do local onde se situam.

Se o homem buscou desde o início da história desenvolver as técnicas comunicativas, o atual estágio de desenvolvimento das comunicações as coloca como socialmente necessárias, vitais para indivíduos e organismos coletivos. Nas comunicações convergentes, assim como em todos os serviços regulados considerados essenciais, direito do consumidor e direitos humanos confundem-se, sendo impossível separálos estruturalmente, na medida em que ter acesso a determinados serviços é indispensável à garantia da dignidade humana. Mais precisamente, ter acesso às tecnologias de informação e às redes para o tráfego de conteúdo digital tornou-se imprescindível para a garantia de direitos fundamentais como o direito à informação, à liberdade de expressão, à educação e à cultura. A própria participação nos processos e fluxos de informação é também um direito humano, por ser o ato de comunicar um dos elementos mais importantes da natureza humana, como demonstram a linguagem, a filosofia, o direito, e diferentes campos das ciências.

Esse direito à participação nos processos e fluxos de informação - que desde a década de 1970 vem sendo chamado, por teóricos, de direito à comunicação - pode ser compreendido como um prolongamento lógico do processo constante em direção à liberdade e à democracia. A exigência de circulação de mão dupla, de intercâmbio livre e de possibilidade de acesso e participação dão nova dimensão qualitativa às liberdades comunicativas conquistadas no passado, como a liberdade de expressão e a de informação. Esse conceito se torna ainda mais relevante com a digitalização dos conteúdos e a expansão da internet, imputando aos Estados a responsabilidade de incluir de maneira horizontal o conjunto da população nas redes que permitem o transporte de conteúdos em alta velocidade. "Inclusão digital", nesta perspectiva, é sinônimo de inclusão social, cultural, econômica e política. Conectar as sociedades se tornou praticamente um imperativo ético de nossos tempos. 


\section{Desconstrução do mito}

É nesse contexto e sob esse guarda-chuva conceitual que o filme recém-lançado por quatro importantes organizações da sociedade civil brasileira ${ }^{\mathrm{ii}}$ se insere. Intitulado Freenet e disponível também em versões em inglês e espanhol, o documentário busca apresentar de forma didática e objetiva os inúmeros conflitos que emergem, por um lado, da ampliação do escopo de direitos ligados ao campo da comunicação e das inúmeras possibilidades de novas formas de interação midiática e, por outro, das também variadas formas de supressão e violações de direitos que permeiam a ampla disseminação da internet nos diversos campos da vida individual e social.

A iniciativa das organizações é essencialmente relevante na medida em que desconstrói o mito plantado em diversas áreas do conhecimento durante a última década do século XX, segundo o qual a internet, em função de uma pretensa natureza livre e plural do novo meio de comunicação, tenderia a resolver os problemas ligados à concentração da chamada mídia tradicional, como a televisão ou os grandes veículos impressos. Assim, além de alterar a forma como trocamos informações, a internet transformaria também, por consequência lógica, a própria qualidade da comunicação, pulverizando o poder da mídia tradicional e dando vazão à ampla diversidade existente no país, anteriormente sufocada.

Todavia, passadas quase duas décadas do início da expansão da rede mundial de computadores, as diversas formas de controle revelam-se cada vez mais robustas e eficazes, implodindo a ideia da natureza democratizante da internet, seja por meio do controle da infraestrutura de telecomunicações, seja pelo domínio dos sistemas operacionais e aplicativos, ou ainda, pelo constrangimento à circulação de conteúdos para uso próprio e educacional.

Para apresentar um panorama amplo dessas questões, o documentário navega por cinco subtemas, a partir de entrevistas com alguns dos mais importantes especialistas nacionais e internacionais, além da reportagem de casos emblemáticos no Brasil, Quênia, Índia, China, EUA e Uruguai, que ajudam a compreender o curso da disputa pelo futuro da internet e os lances com potencial para aprofundar a captura da web por interesses privados - nacionais ou internacionais - ou, inversamente, para afirmar o caráter essencial de uma rede livre e aberta, tanto para indivíduos quanto para as sociedades de forma geral.

\section{Desigualdade e formas de controle}

O tema mais visível e compreensível para o público em geral é também o primeiro a ser abordado. Trata-se do 'acesso à internet' propriamente dito, ou seja, da efetiva capacidade de uma sociedade fazer com que todos os seus cidadãos tenham acesso em condições razoáveis, ou, visto de outra forma, em condições mínimas de igualdade. Contudo, se chegamos ao estágio de uma percepção social praticamente unânime em relação à necessidade de universalização da internet (como já define inclusive o recente Marco Civil da Internet, aprovado em 2014), as visitas realizadas pela equipe do filme a localidades mais pobres ou desprovidas de qualquer infraestrutura de telecomunicações no Brasil (na Amazônia e no bairro de Paraisópolis, em São Paulo), no Quênia ou nos bairros pobres de Detroit, nos EUA, revelam as altíssimas disparidades de acesso entre as classes ricas e pobres. Nesse cenário, se perpetuam e reafirmam as desigualdades clássicas da pirâmide social do Terceiro Mundo, na medida em que aqueles já possuidores de meios e formas de comunicação passam a ter, também nesse novo meio, melhores condições de acesso e fruição das possibilidades comunicativas.

ii Intervozes - Coletivo Brasil de Comunicação Social; Idec - Instituto Brasileiro de Defesa do Consumidor; Instituto Nupef - Núcleo de Pesquisas, Estudos e Formação; e ITS Rio - Instituto de Tecnologia e Sociedade do Rio de Janeiro. 
O tema do acesso é de fácil compreensão e por isso sua escolha para a abertura, mas o documentário aborda com didatismo outras quatro temáticas igualmente relevantes. Três delas, por sua forte interdependência na prática - 'liberdade de expressão', 'privacidade' e 'acesso a conteúdos' - são encadeadas de forma a apresentar as estratégias atuais das nações hegemônicas (em especial dos EUA) e das empresas de telecomunicações e mídia para exercerem controle sobre a rede, muitas vezes violando liberdade e direitos consagrados e já amplamente positivados no ordenamento jurídico nacional e internacional.

No caso da liberdade de expressão, direito fundador das democracias modernas, são relatados casos de violações de diferentes naturezas, como a censura estatal chinesa, que bloqueia páginas eletrônicas e aplicativos que são incômodos ao governo daquele país, e casos de censura judicial, através da qual em geral personagens graúdos da política e da economia buscam impedir a circulação de determinadas notícias que lhes são inconvenientes. Não são poucos os casos dessa natureza registrados no Brasil, mas nossa tradição ainda incipiente na defesa dos direitos civis os tornam quase invisíveis aos olhos da maioria da população.

O tema da 'privacidade' também é abordado, e não à toa: a entrada de uma massa de milhões de pessoas no universo digital permitiu - e permite cada vez mais - o controle da vida dos indivíduos, de seus hábitos e de seus relacionamentos pessoais e sociais, propiciando a invasão da privacidade em diversos níveis, ensejando desde a monetização de nossas rotinas até a espionagem clássica imperialista, possível graças ao amplo domínio dos EUA sobre a web pela canalização do fluxo de dados naquele país (90\% do tráfego de dados passa por lá) e pela relação íntima de seu governo com as empresas norte-americanas que dominam o mercado mundial de sistemas operacionais (Microsoft e Apple) e de conteúdos e aplicativos (Google e Facebook). Nesse sentido, um dos pontos altos do documentário é a entrevista com Glenn Greenwald, jornalista do The Guardian que, em junho de 2013, revelou ao mundo, por meio das provas coletadas pelo ex-agente da NSA, Edward Snowden, as estratégias de espionagem de diversos chefes de Estado pelos EUA, incluindo a presidenta Dilma Roussef.

Além da privacidade e da liberdade de expressão - direitos consagrados que encontram a sua face no universo digital -, outro tema abordado é o 'acesso a conteúdos'. Afinal - e essa pergunta é apresentada de forma bastante objetiva - de que valem conexões de qualidade eliberdade na internet se não podemos circular e trocar conteúdos, recriá-los e reinventá-los? Não seria exatamente isso o melhor que a rede mundial de computadores pode nos oferecer? Nessa seara a disputa se trava entre, de um lado, as empresas detentoras de direitos autorais, como as major norte-americanas dominantes do mercado audiovisual e fonográfico, as grandes emissoras de televisão e editoras e, de outro, os usuários comuns, cujo compartilhamento e uso para fins pessoais é prática ainda criminalizada, embora lógica e óbvia.

Encontrar a harmonia entre a garantia dos direitos dos autores (dos criadores, não das empresas intermediárias) e o direito de acesso à cultura e à educação não é tarefa fácil, mas transpor a lógica do direito de cópia do mundo analógico para o digital - no qual a cópia possui custo zero e possibilidade de circulação inesgotável - parece não ser o caminho recomendável, e pode chegar a casos absurdos como o relatado no documentário. Trata-se de um estudante da Faculdade de Filosofia, Letras e Ciências Humanas da USP que foi perseguido judicialmente pela indústria reprográfica nacional por manter uma página eletrônica com livros da área, muitos deles esgotados há tempos e raros nas bibliotecas. Vale lembrar, embora não haja menção a isso no filme, que há tempos setores da sociedade tentam alterar a legislação brasileira de direitos autorais para permitir o uso justo dos conteúdos que circulam na web - para fins pessoais e educativos, por exemplo - mas a indústria do copyright tem conseguido impedir todas as iniciativas nessa direção.

Por fim, Freenet aborda um tema novo, mas cuja relevância parece impor a definição de um novo princípio jurídico. Trata-se da 'neutralidade de rede', ou seja, o princípio de arquitetura de rede que determina aos provedores de acesso o dever de tratar os pacotes de dados que trafegam em suas redes de forma isonômica, não os discriminando em razão de seu conteúdo ou origem. Isso quer dizer que uma operadora não pode privilegiar o tráfego deste ou daquele aplicativo em detrimento de outro de mesma natureza. 
Essa questão é especialmente relevante, pois a violação do princípio da neutralidade de rede, caso levada às últimas consequências, pode tornar a internet uma espécie de TV por assinatura, em que usuários não teriam acesso a todos os conteúdos da rede, mas somente àqueles permitidos pelas operadoras. Ou teriam acesso a alguns conteúdos com velocidades maiores ou menores em detrimento de outros. Vale lembrar que, embora o Marco Civil da Internet tenha reafirmado o princípio da neutralidade de rede, as operadoras já oferecem pacotes que asseguram somente a fruição de aplicativos específicos, objetos de acordo comercial entre elas e as empresas proprietárias dos aplicativos. A prática, por enquanto, é comum especialmente nos pacotes de dados dos serviços de telefonia celular, mas caso as conexões fixas passem a ter franquia de dados - como atualmente se especula - veremos a proliferação das ofertas também para os usuários residenciais. Seria, de certa forma, o fim da internet como a conhecemos até hoje.

Mas se a disputa pelo futuro da web é dura, nem tudo está perdido. Como o próprio documentário revela, há inúmeras frentes de resistência que buscam reafirmar a liberdade e os direitos vinculados ao acesso e ao uso da internet. É o caso, por exemplo, das comunidades que se organizam para reivindicar e obter acesso à internet no Brasil, no Quênia e nos EUA; das políticas públicas inspiradoras implementadas pelo Uruguai, da difusão de licenças de conteúdo baseadas no compartilhamento conhecidas como Creative Commons, da disseminação do uso da criptografia para reduzir as possibilidades de vigilância e violação de privacidade, entre outros.

Nessa disputa de escala mundial - e é nessa escala que a governança da internet se realiza - as forças se organizam e buscam fazer valer seus interesses. De um lado, os possíveis usuários e as centenas de milhões de pessoas ainda desprovidas de acesso; de outro, as corporações internacionais de aplicativos, de conteúdos e de telecomunicações. A disputa é dura, mas o primeiro passo é garantir que as sociedades compreendam os bens e os valores em jogo, e para isso Freenet dá uma grande contribuição. Vale a pena assistir e compartilhar. 